\title{
Neural computing for a low-frictional coatings manufacturing of aircraft engines' piston rings
}

\author{
Emilia Wołowiec-Korecka ${ }^{2}$ (D) Piotr Kula ${ }^{1,2} \cdot$ Sylwester Pawęta ${ }^{1,2} \cdot$ Robert Pietrasik $^{1,2} \cdot$ Jacek Sawicki $^{1,2} \cdot$ \\ Antoni Rzepkowski ${ }^{1}$
}

Received: 6 June 2017 / Accepted: 31 December 2018/ Published online: 19 January 2019

(C) The Author(s) 2019

\begin{abstract}
The "boost-diffusion" low-pressure nitriding used to low-frictional coatings manufacturing of aircraft engines' piston rings is a nonsteady-state process; therefore, designing and prediction of the process' kinetics by analytical solutions of Fick's equations or numerical methods of diffusion are difficult, due to the nonlinear relationship between the diffusion coefficient and the rate of diffusion as well as nonsteady-state boundary conditions. The best solution in this case, as the practice and theory indicate, is computer-aided design based on neural networks. The paper describes neural network model and its training procedures based on data mining in the application to the monitoring and control of low-pressure nitriding process for creation of low-frictional coatings on gray irons and steels used for the piston rings manufacturing. The goal was to study the usefulness of the multilayer feed-forward perceptrons and radial basis function of neural networks for modeling of multiphase kinetic diffusion for low-pressure nitriding. As it was shown, the use of specialist networks that designate single features gives more accurate prediction results than the use of general networks that design several features at the same time. It has been proved that it is possible to construct an industrial application of the low-pressure nitriding based on artificial neural networks. The results of the research will be the basis for the development of innovative, specialized software supporting the design of gradient low-friction layers based on the FineLPN low-pressure nitriding and consequently the design of intelligent supervision over their manufacturing technology.
\end{abstract}

Keywords Low-pressure nitriding $\cdot$ Low-frictional coatings $\cdot$ Neural networks $\cdot$ Modeling

\section{Introduction}

In recent years, dynamic development of small aircrafts has been observed globally. The planes are mainly intended for recreation purposes as air taxis, agricultural planes and as small cargo aircrafts. Considering the power necessary to drive the planes, piston engines are used. The costs of purchasing and using piston engines constitute another aspect that determines their use, as the costs are lower than in the case of turbine engines. The cost of fuel is the main cost component related to using combustion engines. Some

Emilia Wołowiec-Korecka

emilia.wolowiec@p.lodz.pl

1 Hart-Tech Ltd., 45 Niciarniana Street, 92320 Lodz, Poland

2 Institute of Materials Science and Engineering, Lodz University of Technology, 1/15 Stefanowski Street, 90924 Lodz, Poland tests revealed that the majority of mechanical losses in a piston engine are caused by friction in the piston-cylinder assembly, while the most of these losses result from the piston rings rubbing against the cylinder-bearing surface. It impacts the engine life and determines its service life between overhauls. Piston rings, which also remove heat from the piston to the cylinder, make the essential sealing from the point of view of friction and lubrication $[1,2]$.

The friction force between the surface of the piston and the cylinder-bearing surface depends on the material of the piston and bearing surface, as well as on the lubrication conditions and value of the normal force pressing the piston to the cylinder-bearing surface. The friction between the piston and the bearing surface is not a stabilized fluent friction but occurs partly under boundary conditions. The piston works with the bearing surface at an elevated temperature, which reduces oil viscosity and causes further deterioration of the friction conditions [3, 4]. 
Materials used for piston rings have to meet a number of requirements that tend to be contradictory. A material for piston rings should have a low coefficient of friction when sliding on the cylinder-bearing surface material, whereby the working surface of the ring should maintain high smoothness. Some additional requirements include resistance to high load within the entire range of temperatures occurring in the engine at very limited lubrication and low tendency to seizing under boundary friction conditions that may occur in the engine. A continuous surface with high smoothness should be formed on the ring surface under normal working conditions of the engine (quick wear-in). The resulting smooth surface should demonstrate high oilwettability and should hold oil well. The material should also reveal a certain degree of self-lubrication. No largesized particles should be separated as the material is subjected to wear. Moreover, the material should have sufficient bending and compression strength and high elasticity, with no plastic strain. Due to the presence of corrosive factors in the fuel and suctioned air, the material should reveal corrosion resistance within the entire range of the engine working temperatures [5-8].

At present, there is no material that would perfectly meet all these requirements. Cast iron is the most popular material used for piston rings, as well as alloy steel is also used for making rings by cold-rolling of steel tape. In order to improve cooperation between the piston ring and the cylinder sleeve, coatings are applied. They include chromium and/or chromium-molybdenum galvanic coats as well as flame or plasma sprayed and CVD ones [9-14]. The nitriding process is also used for surface treatment of rings made mainly of steel [15-18]. Chromium-based coats are most common; however, they are also the most dangerous ones for the natural environment, as $\mathrm{Cr}^{6+}$ is used [19-21].

The alternative, innovative solution to the coatings mentioned above is low-frictional coatings on piston rings obtained in the hybrid process that combines simultaneous sintering nanoparticles $\mathrm{MoS}_{2}$, reduced graphene oxides (rGO) with iron nitrides with the low-pressure nitriding FineLPN. Layered inclusions of nanoparticles in such coating together with the self-lubrication by hydrogen phenomenon offer the decreasing the dry friction coefficient even twice [22-25]. The use of low-pressure nitriding as the dominating thermal process protects the nanoparticles against thermochemical degradations during manufacturing as well as helps to harden the top coat to the required depth and enables reaching the controlled spectrum of compressive residual stresses that is of key importance from the point of view of fatigue strength and resistance to hydrogen wear [26, 27].

FineLPN low-pressure nitriding is a nonequilibrium process, thus Fick's diffusion law, which describes the transport of nitrogen atoms needed to create a favorable surface structure through analytical equations or numerical methods, is difficult due to the nonlinear relationship between the diffusion coefficient and the diffusion rate as well as nonsteady boundary conditions. The problem is additionally complicated by a large variety of steel and cast iron grades (different chemical alloying), which strongly influence the diffusion rate and phase transformations. The best solution in this case, as the practice and theory indicate, is a computer-aided design based on neural networks. The assumptions to the neural network model and its applications to the low-pressure nitriding of tools have been presented in several former papers [28-31]. The knowledge analysis in the field shows that the use of neural networks to predict the resulting properties of the technological surface layer of steel and low-pressure-nitrided iron (LPN) for aerospace applications has not been considered so far. Despite the wide use of neural networks in the material science [32, 33], including heat treatment [34-36], in nitriding they were mainly used in gas and ion nitriding (plasma) [37-41]. There is no information on the models of low-pressure nitriding in the literature. The difficulty of the problem results from both the nonstationary boundary conditions (nonstationary boundary conditions also excludes the use of analytical models based on conventional mathematical equations) as well as the huge multiparametry of the phenomenon (process temperature, segmentation, segment times, numerous alloy additions, etc.). The present paper describes a neural network model and its training procedures based on data mining in the application to the monitoring and control of low-pressure nitriding process for creation of low-frictional coatings on gray irons and steels used for the piston rings manufacturing. These types of materials have so far not been the subject of optimization of the FineLPN low-pressure nitriding process. They are also not classic materials dedicated to the nitriding process, and hence the kinetics of nitrogen profile development and structural structure of these layers have not been studied yet. The aim of the work is to confirm the hypothesis that it is possible to construct an industrial application of low-pressure nitriding based on artificial neural networks and in particular to investigate the suitability of specific neural network architectures: multilayer perceptron networks (MLPs) and radial basis-based networks (RBF) for modeling of multiphase diffusion kinetics in low-pressure nitriding.

\section{Materials and methods}

\subsection{Field experiment}

The principal phases that form during the nitriding of iron base materials (steels) are first a solid solution of alpha-iron 
$(\alpha)$, which has a maximum solid solubility of about $0.11 \%$ nitrogen. The next phase that forms is gamma-prime $\left(\gamma^{\prime}\right)$. This is a phase field that has a solubility range of about $5.1-6.1 \%$ nitrogen and is usually represented by the chemical formula $\mathrm{Fe}_{4} \mathrm{~N}$ (Fig. 1). The third phase for consideration is epsilon $(\varepsilon) \mathrm{Fe}_{3-2} \mathrm{~N}$, and it may have equilibrium nitrogen contents of 7 to $8 \%$ nitrogen, depending on the temperature at which it forms. There may be a "white layer," that appears microscopically, on the surface of the nitrided material, which is composed of $\varepsilon$ and/or $\gamma^{\prime}$. These phases in the white layer may have desirable or undesirable characteristics depending on the intended application [26]. Therefore, it is important to be able to control the nitriding process to produce the desired structure in terms of the composition of the white layer, and if a white layer is to be present or not.

\subsection{Data}

The data for experiments were collected from the nitrided layers obtained after thermochemical treatment of structural steels and cast iron EN 41CrAlMo7 (1.8509), EN 42CrMo4 (1.7225), 50HS (1.5026), PENTHOR 854, S14, L11, XTB samples. The chemical composition of the materials has been summarized in the table (Table 1). The nitriding process parameters under reduced pressure are shown in the table (Table 2). The nitrided layers were

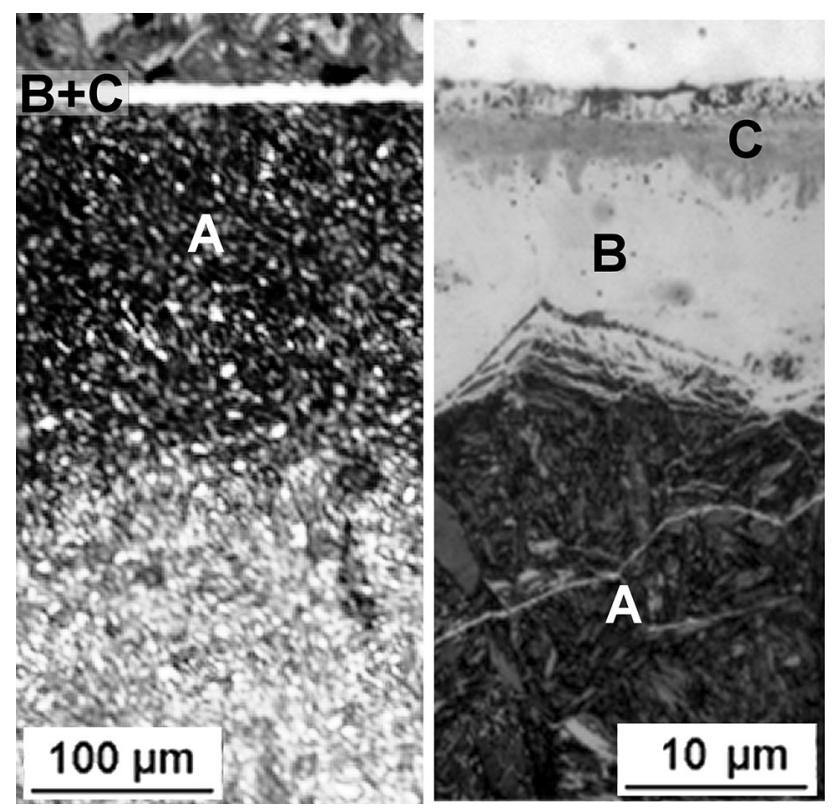

Fig. 1 View of the nitrided layer formed on 41CrAlMo7 steel (1.8509) in order to obtain a low friction coating on the piston rings of the aircraft engines. As one can observe: a the hardened diffusion zone $(\alpha)$, responsible for surface pressure and fatigue strength; b nitride zone $\left(\gamma^{\prime}\right)$; c nitride zone $\left(\gamma^{\prime}+\varepsilon\right)$ reinforced with low-friction $\mathrm{MoS}_{2}$ and rGO particles. Prepared in Jasc Paint Shop Pro. No published tested for the following properties: surface hardness [HV], diffusion layer thickness $(\alpha)[\mu \mathrm{m}]$, nitride phase thickness Fe4N $\left(\gamma^{\prime}\right)[\mu \mathrm{m}]$.

\subsection{Data preprocessing}

Both the process parameters and the characteristics of the nitrided material determine the kinetics of the nitrided layer growth. In addition, both these groups determine the resulting (exploitation) properties of nitrided steels and cast irons. A number of scientists point out that the critical parameters of the nitriding process include temperature, process organization in the boost-diffusion segments and the times of these segments [26, 28, 42, 43]. In addition, Filetin et al. [44] pointed out that at the current state of knowledge, the choice of nitriding parameters is largely based on the experimenter's experience. Due to construction and technological reasons, certain parameters of the LPN process (pressure, flow) are fixed. Hence, the inclusion in the model is not justified (values are constant for all processes).

Alloy additions are important for the nitriding process, causing the nitriding kinetics of each material to run individually. Structural steels from which the rings are produced contain the alloying elements in quantities such as: (C: $0.3-0.6 \%, \mathrm{Mn}: 0.4-0.7 \%, \mathrm{Si}: 0.2-1.4 \%)$ while the cast iron contain additives in quantities $(\mathrm{C}>2.11 \%, \mathrm{Mn}$ : $0.6-1.3 \%$, Si: $1.95-2.6 \%)$. Thus, these materials differ from each other significantly. Khalaj in his work on prenitrided steels such as 1.2210, 1.2510, 1.2344, 1.3343, 1.2080 shows a significant influence of their alloy additions: C, Mn, Si, S, P, Cr, Ni, Mo, V, W, and the effectiveness of these steel [45]. In case of steels and cast irons described in this paper $(1.8509,1.7225,1.5026$, PENTHOR 854, S14, L11, XTB), nitriding for aerospace applications has so far not been attempted. Therefore, the assumption concerning alloy additives was adopted, analogous to the assumption of the work [45]. Because the effectiveness of these materials is determined by the content of elements $\mathrm{C}, \mathrm{Mn}, \mathrm{Si}, \mathrm{Cr}, \mathrm{Ni}, \mathrm{Mo}, \mathrm{Al}, \mathrm{V}, \mathrm{W}$, Ti, hence they were classified as network parameters. In the case of cast irons, it was observed that the carbon was mainly concentrated in graphite formations and therefore not relevant to the nitriding process. Nevertheless, the carbon content of the material is crucial for identifying the material as steel or cast iron. A knowledge base for building neural networks has been divided into two parts:

1. The data containing test results for $\mathrm{EN} 41 \mathrm{CrAlMo} 7$ (1.8509), EN 42CrMo4 (1.7225), 50HS (1.5026) and PENTHOR 854 steels have been used to design the nitriding simulation of structural steels. 
Table 1 Materials used for nitriding in lower pressure research (wt $\%$ )

\begin{tabular}{|c|c|c|c|c|c|c|c|c|c|c|c|}
\hline Material & $\mathrm{C}(\%)$ & $\operatorname{Mn}(\%)$ & $\mathrm{Si}(\%)$ & $\mathrm{Cr}(\%)$ & $\mathrm{Ni}(\%)$ & Mo (\%) & $\mathrm{Al}(\%)$ & $\operatorname{Mg}(\%)$ & $\mathrm{V}(\%)$ & $\mathrm{W}(\%)$ & $\mathrm{Ti}(\%)$ \\
\hline EN 41CrAlMo7 (1.8509) & 0.39 & 0.45 & 0.27 & 1.50 & 0.25 & 0.20 & 0.90 & 0.00 & 0.00 & 0.00 & 0.00 \\
\hline $\mathrm{EN} 42 \mathrm{CrMo} 4$ (1.7225) & 0.42 & 0.55 & 0.27 & 1.05 & 0.30 & 0.20 & 0.00 & 0.00 & 0.00 & 0.00 & 0.00 \\
\hline 50HS (1.5026) & 0.5 & 0.45 & 1.00 & 1.05 & 0.40 & 0.00 & 0.00 & 0.00 & 0.00 & 0.00 & 0.00 \\
\hline PENTHOR 854 & 0.55 & 0.70 & 1.40 & 0.65 & 0.00 & 0.00 & 0.00 & 0.00 & 0.00 & 0.00 & 0.00 \\
\hline S14 & 3.5 & 0.60 & 2.55 & 0.30 & 1.20 & 0.50 & 0.00 & 0.05 & 0.00 & 0.00 & 0.00 \\
\hline L11 & 2.8 & 1.00 & 2.20 & 1.08 & 0.50 & 0.65 & 0.00 & 0.00 & 0.00 & 0.00 & 0.00 \\
\hline ХTB & 3.05 & 1.25 & 1.95 & 0.55 & 0.40 & 0.00 & 0.00 & 0.00 & 0.00 & 0.75 & 0.23 \\
\hline
\end{tabular}

Table 2 Parameters of nitriding processes in reduced pressure

\begin{tabular}{lll}
\hline Process no. & Temperature $\left({ }^{\circ} \mathrm{C}\right)$ & Process organization \\
\hline 1 & 540 & $6 \mathrm{~A}$ \\
2 & 540 & $6 \mathrm{~A} / 2 \mathrm{D}$ \\
3 & 540 & $8 \mathrm{~A} / 2 \mathrm{D}$ \\
4 & 540 & $4 \mathrm{~A} / 2 \mathrm{D} / 4 \mathrm{~A}$ \\
5 & 510 & $6 \mathrm{~A}$ \\
6 & 560 & $6 \mathrm{~A} / 2 \mathrm{D}$ \\
7 & 560 & $4 \mathrm{~A} / 2 \mathrm{D}$ \\
8 & 560 & $2 \mathrm{~A} / 2 \mathrm{D} / 2 \mathrm{~A}$ \\
10 & 540 & $12 \mathrm{~A}$ \\
11 & 560 & $9 \mathrm{~A}$ \\
12 & 510 & $12 \mathrm{~A}$ \\
\hline
\end{tabular}

A, saturation (ammonia dosing); D, annealing (no ammonia dosing, nitrogen dosing). The number before the letter indicates the number of hours per process

2. The data containing test results for S14, L11, XTB cast irons have been designed to design a simulation algorithm of the cast iron nitriding processes.

\section{Artificial neural networks}

ANN are inspired from the human nervous system and are widely used toward nonlinear modeling [46, 47]. They are part of computational intelligence. The basic cell of artificial neural networks is the neuron, which refers to the structure of the living neuron. Each neuron accepts a set of numerical inputs from various sources and base on their information. Neuron stimulation is transformed by a fixed activation function (neuron transition function), and its value is the final output value (output signal) of the neuron. An artificial neural network maps even very complex functions, and its typical task is to approximate the functions of many variable functions in order to map the set of input variables to a set of output variables [48, 49]. The ways of connecting neurons between themselves and their mutual interactions resulted in creating different types of networks.

\subsection{Multilayer feed-forward (MLFF) ANN}

The multilayer perceptron (MLP) is composed of perceptron neurons. In combination with the backpropagation algorithm [50], it is one of the most popular artificial neural network models used and can be used to approximate almost every mapping. In rare occasions, there are two or more hidden layers in it, for one hidden layer is sufficient for mapping of each continuous function [48, 51] and of data classification [52-54]. The characteristic feature of single-layered unidirectional network is the ability to distinguish their three parts: an input layer that accepts input signals, hidden layers (one or more), and an output layer that provides a network response (output signal). Data signals are transmitted from layer to layer and transformed at each stage. Multilayered networks often use the nonlinear function of sigmoidal activation, and thus constitute Rosenblatt's generalization of the perceptron [52, 55]. In practice, the input and hidden layer neurons comprise the sigmoid function and the output neurons have a linear function.

\subsection{RBF network}

The radial basis function (RBF) is similar in structure to the MLP network. The distinctive feature between the perceptron neutron and the radial neuron is the activation function [56]. Radial neuron performs a radial change function around the selected center, assuming nonzero values only around this center. Thanks to this, radial networks are complementary to sigmoidal networks [57].

Since there is no mathematical model of multiphase diffusion equations occurring during low-pressure nitriding, and the nature of functions describing these 
dependencies was also not well-researched, this study has investigated the suitability of both MLP and RBF architectures.

\section{ANN training algorithms}

\subsection{Algorithm of backpropagation method}

The momentum backpropagation method (MBP) is a basic method of training multilayer neural networks [50, 58-61]. Although not being one of the fastest known training algorithms, it has advantages that determine its popularity. In this paper, it was used in an iterative way. During the training process, a number of training sets were presented and on the basis of the network response, the weight values were corrected so that, ultimately, the error made by the network was smaller than the value set before. Correction of the network weight vector is based on the minimization of the error measure function (SSE), which has been defined as the sum of the squared differences on the outputs of the network. The network weights were modified using the rule of the fastest decline according to the formulae:

$$
\begin{aligned}
\varepsilon_{i}^{(k)}(n) & =f(x) \\
& =\left\{\begin{array}{l}
\varepsilon_{i}^{(L)}(n), \quad k=L \\
\sum_{m=0}^{N_{i+1}} \delta_{m}^{(k+1)}(n) \cdot \delta_{m i}^{(k+1)}(n), \quad k=1 \ldots L-1
\end{array}\right.
\end{aligned}
$$

$$
\varepsilon_{i}^{(L)}(n)=d_{i}^{(L)}(n)-y_{i}^{(L)}(n)
$$

$\delta_{i}^{(k)}(n)=\varepsilon_{i}^{(k)}(n) \cdot f^{\prime}\left(s_{i}^{(k)}(n)\right)$

$$
\begin{aligned}
w_{i j}^{(k)}(n+1)= & w_{i j}^{(k)}(n)+2 \mu \varepsilon_{i}^{(k)}(n) \cdot f^{\prime}\left(s_{i}^{(k)}(n)\right) \cdot x_{j}^{(k)}(n) \\
& +\alpha\left(w_{i j}^{(k)}(n)-w_{i j}^{(k)}(n-1)\right)
\end{aligned}
$$

where $\varepsilon_{i}^{(L)}$ —error on the $i$-th network output, $\varepsilon_{i}^{(k)}$-error on output of $i$-th neuron in the $k$ layer, $w_{i j}^{(k)}-i j$ weight value in the $k$ layer, $s_{i}^{(k)}$-activation function of $i$-th neuron in the $k$ layer, $\mu$-training coefficient, $x_{j}^{(k)}$ —entry of the $j$-th neuron into the $k$ layer, $d_{i}^{(L)}$-expected response on the $i$-th network output, $y_{i}^{(L)}$-the real answer on the $i$-th network output, $\alpha \in(0,1]$-momentum coefficient.

\subsection{Broyden-Fletcher-Goldfarb-Shanno's method}

The Broyden-Fletcher-Goldfarb-Shanno's

(BFGS) method uses Newton's method [60], however, with some modifications. Both methods are based on defining an error gradient. Yet, the Newton's method requires the calculation of Hessian matrix, while the BFGS method is based on an approximation of Hessian matrix inverse rather than its exact value. This is a great advantage in case of training large networks since the calculating Hessian matrix is a highly time-consuming operation. Training neural network according to this method has been carried out according to the formulae:

$$
\begin{aligned}
V_{t}= & V_{t-1}+\left(1+\frac{\left(r^{t}\right)^{\mathrm{T}} V_{t-1} r^{t}}{\left(s^{t}\right)^{\mathrm{T}} r^{t}}\right) \frac{s^{t}\left(s^{t}\right)^{\mathrm{T}}}{s^{t} r^{t}} \\
& -\frac{s^{t}\left(r^{t}\right)^{\mathrm{T}} V_{t-1}+V_{t-1} r^{t}\left(s^{t}\right)^{\mathrm{T}}}{\left(s^{t}\right)^{\mathrm{T}} r^{t}}
\end{aligned}
$$

where

$r^{t}=\nabla E\left(w^{t}\right)-\nabla E\left(w^{t-1}\right)$

$s^{t}=w^{t}-w^{t-1}$

$w^{t}=w^{t-1}-\eta V^{t} \nabla E\left(w^{t-1}\right)$

The value of cross-entropy, in accordance with the formulae (9) and (10), was taken as the error function in the steel assessment networks.

$\widehat{H}=\sum_{i=1}^{N} p_{i} \cdot \log \left(\frac{1}{y_{i}}\right)$

$y_{1}+y_{2}+\cdots+y_{N}=1$

where $p_{i}$-the actual probability of realization of the $i$-th value, and $y_{i}$-output values of the network.

\section{Experiments}

\subsection{ANN for predicting the properties of nitrided layers}

Data for the training base were obtained from tests of nitrided layers obtained after thermochemical treatment on samples of structural steel and cast iron, the chemical composition of which is summarized in the table (Table 1). Standardized input values: structural steels chemical composition (C, Mn, Si, Cr, Ni, Mo, Al, V, W, Ti) [\%], process temperature $T\left[{ }^{\circ} \mathrm{C}\right]$, and process segmentation (times of two saturation segments $\mathrm{A} 1$ [h], A2 [h] and one segment of annealing D1 [h]). For V, W, Ti data for structural steels, no variability was observed and discarded from further work. Data output left unchanged: surface hardness $H[\mathrm{HV}]$, diffusion layer thickness ECD [ $\mu \mathrm{m}]$, and $\gamma^{\prime}$ phase thickness $G[\mu \mathrm{m}]$.

Patterns were randomly divided into training, testing and validation sets: $70 \%$ - set of training patterns, $15 \%$ 
set of test patterns, $15 \%$ - set of validating patterns. The set of training patterns has been designed to train the network directly and adjust the weights of the network accordingly. At the same time as training, progress in training was checked on the test set of the validation set, on the basis of which the weights were not corrected. If the test error began to rise after the initial period of decrease, the training process termination was considered. Ultimately, the quality of the trained network was assessed on the basis of its response to input from the validation set that did not participate in the training or testing process.

The separate neural networks or networks were developed using analytics software (Statistica, Tibco Software Inc.) [62] to determine the value of the surface hardness, the diffusion layer thickness and $\gamma^{\prime}$ phase thickness. In order to find the optimal neural network for each of the properties of nitrided layers, from 2000 up to 6000 randomly generated MLP and RBF structured networks with different activation functions have been trained. The following training algorithms were used: the backpropagation method and BFGS algorithm. Parameters of training method and quality for individual properties are presented in the table (Table 3). Network quality is the linear correlation coefficient between the values measured experimentally and theoretical values (calculated using the model) and its value is within the range [0,1]. In other words, the closer the network quality to 1 , the network responses are closer to the expected values.

The input values for cast iron and structural steels have been standardized alike. For data on $\mathrm{Al}$ and $\mathrm{V}$, no variability was observed and thus they have been discarded from further work. The output data were left unchanged. In order to find an optimal solution for each of the properties of the nitrided layer, 2000-10,000 randomly generated MLP and RBF networks with different activation functions have been trained. The following training algorithms were used: backpropagation of errors and BFGS algorithm.
Parameters of training method and quality for individual properties have been presented in the table (Table 4).

\subsection{Neural networks for determining process segmentation based on the technological requirements of the surface layer}

The same experimental data were used to construct the network determining the process segmentation based on the expected technological properties of the top layer. The input values were all the data taken from the collections, except for the process time data, which in this case were the output data. The values of all input data have been standardized. The output data were left unchanged. The neural networks were created to determine: the values of the time of the segment first nitriding, the time of the segment annealing segment and the time of the segment second nitriding. In order to find the optimal neural network, 20,000 randomly MLP and RBF networks have been generated. Subsequently, the best of them was chosen as a quality criterion, adopting the quality indicators for training, test and validation sets. The training results for structural steels and cast irons have been shown in the tables (Tables 5, 6).

\section{Results}

The results (Table 7) show the training results of neural networks for predicting surface hardness of structural steels and cast iron after nitriding under reduced pressure. Tables 8 and 9 show the results of network training to predict the thickness of diffusion layers and the thickness of $\gamma^{\prime}$ nitrides. The results of neural networks training in order to determine process segmentation based on the technological requirements of the top layer are presented in Table 10 .

Table 3 Neural networks parameters for surface hardness determination, diffusion layer thickness $(\alpha)$, thickness of nitrides phase $\left(\gamma^{\prime}\right)$ in construction steels

\begin{tabular}{|c|c|c|c|c|c|c|c|c|}
\hline $\begin{array}{l}\text { Nitrided layer } \\
\text { properties }\end{array}$ & $\begin{array}{l}\text { Network } \\
\text { architecture }\end{array}$ & $\begin{array}{l}\text { Training } \\
\text { quality }\end{array}$ & $\begin{array}{l}\text { Testing } \\
\text { quality }\end{array}$ & $\begin{array}{l}\text { Validation } \\
\text { quality }\end{array}$ & $\begin{array}{l}\text { Training algorithm } \\
\text { (iterations) }\end{array}$ & $\begin{array}{l}\text { Error } \\
\text { function }\end{array}$ & $\begin{array}{l}\text { Hidden neurons } \\
\text { activation }\end{array}$ & $\begin{array}{l}\text { Output neurons } \\
\text { activation }\end{array}$ \\
\hline$H$ & MLP 11-9-1 & 0.9996 & 0.9979 & 0.8746 & BFGS 82 & SOS & Tanh & Linear \\
\hline \multirow[t]{2}{*}{ ECD } & $\begin{array}{l}\text { MLP 11-4- } \\
\text { 1A }\end{array}$ & 0.9732 & 0.9885 & 0.9662 & BFGS 41 & SOS & Exponential & Logistic \\
\hline & $\begin{array}{l}\text { MLP 11-4- } \\
\text { 1B }\end{array}$ & 0.9707 & 0.9862 & 0.9739 & BFGS 45 & SOS & Exponential & Logistic \\
\hline \multirow[t]{2}{*}{$G$} & MLP 11-12-1 & 0.9575 & 0.9916 & 0.8945 & BFGS 21 & SOS & Tanh & Linear \\
\hline & MLP 11-4-1 & 0.9569 & 0.9981 & 0.9982 & BFGS 29 & SOS & Tanh & Tanh \\
\hline
\end{tabular}

$H$, surface hardness; ECD, diffusion layer thickness; $G$, thickness of nitrides phase; SOS, the sum of least squares; tanh, tangent curve 
Table 4 Neural networks parameters for surface hardness determination, diffusion layer thickness $(\alpha)$, nitrides phase thickness $\left(\gamma^{\prime}\right)$ in cast iron

\begin{tabular}{lllllllll}
\hline $\begin{array}{l}\text { NHitrided layer } \\
\text { properties }\end{array}$ & $\begin{array}{l}\text { Network } \\
\text { architecture }\end{array}$ & $\begin{array}{l}\text { Training } \\
\text { quality }\end{array}$ & $\begin{array}{l}\text { Testing } \\
\text { quality }\end{array}$ & $\begin{array}{l}\text { Validation } \\
\text { quality }\end{array}$ & $\begin{array}{l}\text { Training algorithm } \\
\text { (iterations) }\end{array}$ & $\begin{array}{l}\text { Error } \\
\text { function }\end{array}$ & $\begin{array}{l}\text { Hidden neurons } \\
\text { activation }\end{array}$ & $\begin{array}{l}\text { Output neurons } \\
\text { activation }\end{array}$ \\
\hline$H$ & MLP 11-4-1 & 0.9993 & 0.9047 & 0.9998 & BFGS 65 & SOS & Tanh & Tanh \\
ECD & MLP 11-4-1 & 0.9792 & 1.0000 & 1.0000 & BFGS 32 & SOS & Tanh & Linear \\
$G$ & MLP 11-4-1 & 0.7810 & 0.9842 & 1.0000 & BFGS 9 & SOS & Logistic & Exponential \\
\hline
\end{tabular}

$H$, surface hardness; ECD, diffusion layer thickness; $G$, thickness of nitrides phase; SOS, the sum of least squares; tanh, tangent curve

Table 5 Parameters of the neural networks in order to determine nitride segmentation in construction steels

\begin{tabular}{llllllll}
\hline Network name & $\begin{array}{l}\text { Training } \\
\text { quality }\end{array}$ & Testing quality & $\begin{array}{l}\text { Validation } \\
\text { quality }\end{array}$ & $\begin{array}{l}\text { Training } \\
\text { algorithm } \\
\text { (iterations) }\end{array}$ & Error function & $\begin{array}{l}\text { Hidden neurons } \\
\text { activation }\end{array}$ & $\begin{array}{l}\text { Output neurons } \\
\text { activation }\end{array}$ \\
\hline MLP 11-4-3A & 0.9092 & 0.6260 & 0.6484 & BFGS 84 & SOS & Logistic & Linear \\
MLP 11-4-3B & 0.8944 & 0.6232 & 0.6516 & BFGS 56 & SOS & Logistic & Linear \\
\hline
\end{tabular}

Table 6 Parameters of the neural networks in order to determine nitride segmentation in cast irons

\begin{tabular}{llllllll}
\hline $\begin{array}{l}\text { Network } \\
\text { name }\end{array}$ & $\begin{array}{l}\text { Training } \\
\text { quality }\end{array}$ & $\begin{array}{l}\text { Testing } \\
\text { quality }\end{array}$ & $\begin{array}{l}\text { Validation } \\
\text { quality }\end{array}$ & $\begin{array}{l}\text { Training } \\
\text { algorithm } \\
\text { (iterations) }\end{array}$ & $\begin{array}{l}\text { Error } \\
\text { function }\end{array}$ & $\begin{array}{l}\text { Hidden neurons } \\
\text { activation }\end{array}$ & $\begin{array}{l}\text { Output neurons } \\
\text { activation }\end{array}$ \\
\hline MLP 11-4-3 & 0.9028 & 0.6228 & 1.0000 & BFGS 102 & SOS & Logistic & Tanh \\
MLP 11-8-3 & 0.8812 & 0.6220 & 1.0000 & BFGS 1050 & SOS & Tanh & Logistic \\
\hline
\end{tabular}

Table 7 Table of surface hardness $(H)$ prediction after low-pressure nitriding for selected cases of structural steels and cast irons

\begin{tabular}{|c|c|c|c|c|c|c|}
\hline \multicolumn{7}{|c|}{ Layer thickness $H(\mathrm{HV})$} \\
\hline & \multicolumn{3}{|c|}{ Construction steels } & \multicolumn{3}{|c|}{ Cast irons } \\
\hline & Real & ANN & Abs. difference & Real & ANN & Abs. difference \\
\hline 1 & 996 & 998 & 2 & 345.6 & 344.0 & 1.6 \\
\hline 2 & 439 & 442 & 3 & 375.6 & 378.2 & 2.6 \\
\hline 3 & 549 & 545 & 3 & 344.4 & 342.6 & 1.8 \\
\hline 4 & 695 & 696 & 1 & 338.8 & 338.5 & 0.3 \\
\hline 5 & 436 & 437 & 1 & 300.2 & 301.0 & 0.8 \\
\hline 6 & 320 & 320 & 0 & 330.0 & 327.0 & 3.0 \\
\hline 7 & 821 & 806 & 15 & 398.0 & 398.4 & 0.4 \\
\hline 8 & 838 & 844 & 5 & 384.2 & 392.8 & 8.6 \\
\hline 9 & 506 & 607 & 101 & 372.4 & 372.8 & 0.4 \\
\hline 10 & 683 & 684 & 0 & 399.8 & 409.9 & 10.1 \\
\hline
\end{tabular}

\section{Discussion}

Based on research data from EN 41CrAlMo7 (1.8509), EN 42CrMo4 (1.7225), 50HS (1.5026) and PENTHOR 854 steels, the neural network calculation algorithms have been developed to predict the nitriding processes in structural steels. The training results of these networks are characterized by high training rates (training, testing and validation quality in Tables 3, 4), which gives the high probability of the nontraining outcomes to be appropriate. The validation quality of networks for constructional steels (Table 3) was lower than training and testing quality. According to the literature [60,61, 63], it is the normal situation because during validation the networks gave answers for patterns which they never trained. Therefore, a larger validation error is not a disturbing phenomenon. This situation was not observed for networks to the cast iron nitriding predicting (Table 4). Based on data from the research on the S14, L11, XTB cast irons, the calculation algorithms based on neutron networks have been developed to predict the nitriding processes in cast iron. The training 

diffusion layer (ECD) after lowpressure nitriding for selected cases of structural steels and cast irons
Table 8 Predictive table of

\begin{tabular}{|c|c|c|c|c|c|c|c|c|}
\hline \multicolumn{9}{|c|}{ Diffusion layer thickness $(\alpha)$ ECD $(\mu \mathrm{m})$} \\
\hline & \multicolumn{5}{|c|}{ Construction steels } & \multicolumn{3}{|c|}{ Cast irons } \\
\hline & Real & ANN1 & ANN2 & ANN group & Abs. difference & Real & ANN & Abs. difference \\
\hline 1 & 140 & 156 & 167 & 161 & 21 & 45.0 & 44.8 & 0.2 \\
\hline 2 & 100 & 72 & 75 & 74 & 26 & 40.0 & 40.1 & 0.1 \\
\hline 3 & 70 & 78 & 86 & 82 & 12 & 50.0 & 42.8 & 7.2 \\
\hline 4 & 90 & 92 & 92 & 92 & 2 & 45.0 & 47.0 & 2.0 \\
\hline 5 & 90 & 96 & 94 & 95 & 5 & 50.0 & 50.5 & 0.5 \\
\hline 6 & 80 & 85 & 82 & 84 & 4 & 55.0 & 56.6 & 1.6 \\
\hline 7 & 170 & 166 & 171 & 168 & 2 & 65.0 & 61.4 & 3.6 \\
\hline 8 & 220 & 184 & 181 & 182 & 38 & 40.0 & 41.3 & 1.3 \\
\hline 9 & 110 & 53 & 68 & 60 & 50 & 50.0 & 49.9 & 0.1 \\
\hline 10 & 170 & 172 & 173 & 173 & 3 & 40.0 & 37.9 & 2.1 \\
\hline
\end{tabular}

Table 9 Table of thickness predictions in $\gamma^{\prime}$ phase $(G)$ after low-pressure nitriding for structural steels in selected cases

\begin{tabular}{|c|c|c|c|c|c|c|c|c|}
\hline \multicolumn{9}{|c|}{ Nitride phase thickness $\left(\gamma^{\prime}\right) G(\mu \mathrm{m})$} \\
\hline & \multicolumn{5}{|c|}{ Construction steels } & \multicolumn{3}{|c|}{ Cast irons } \\
\hline & Real & ANN1 & ANN2 & ANN group & Abs. difference & Real & ANN & Abs. difference \\
\hline 1 & 8.0 & 8.0 & 7.2 & 7.6 & 0.4 & 3.4 & 3.0 & 0.4 \\
\hline 2 & 1.0 & 2.3 & 1.0 & 1.6 & 0.6 & 0.6 & 0.5 & 0.1 \\
\hline 3 & 3.0 & 3.3 & 2.5 & 2.9 & 0.1 & 0.6 & 0.5 & 0.1 \\
\hline 4 & 4.0 & 3.4 & 3.4 & 3.4 & 0.6 & 1.7 & 4.0 & 2.3 \\
\hline 5 & 0.5 & 1.6 & 2.0 & 1.8 & 1.3 & 0.6 & 0.5 & 0.1 \\
\hline 6 & 2.0 & 0.6 & 1.4 & 1.0 & 1.0 & 3.1 & 5.0 & 1.9 \\
\hline 7 & 8.0 & 7.7 & 7.8 & 7.7 & 0.3 & 3.9 & 3.0 & 0.9 \\
\hline 8 & 10.0 & 10.8 & 10.3 & 10.6 & 0.6 & 2.3 & 2.0 & 0.3 \\
\hline 9 & 1.0 & 2.7 & 2.6 & 2.6 & 1.6 & 2.5 & 4.0 & 1.5 \\
\hline 10 & 10.0 & 9.6 & 9.3 & 9.5 & 0.5 & 0.5 & 0.5 & 0.0 \\
\hline
\end{tabular}

results of these networks were high. The relative errors for hardness predictions were $2 \%$ (constructional steels) and $1 \%$ (cast iron) and, respectively, $1 \%$ and $4 \%$ for predictions of effective layer thicknesses. In the case of networks with a $\gamma^{\prime}$ phase thickness, the training parameters were less precise than in the case of the previous ones $(15 \%$ and $40 \%$ ).

Predictions obtained from the MLP artificial neural network model were subjected to a sensitivity analysis. The resolution of the control system for temperature was \pm $1{ }^{\circ} \mathrm{C}$, and the time of segment was $\pm 1 \mathrm{~min}$. The global sensitivity analysis carried out in the Statistica [62] program showed that the most important parameters of the model are the temperature $(T)$ and the time of the segment of endurance (segment of annealing) (D1). The effect of the altered values on the accuracy of the prediction of the hardness and the effective case depth were examined. The maximum percentage error on the validation set was found to be $7.2 \%$ and $5.5 \%$, respectively, whereas the maximum percentage error on validation set using the actual (not altered) values was $7.3 \%$ and $5.6 \%$. No significant variation was found.

In addition, the algorithms determining the segmentation of the nitriding process based on the surface layer guidelines have been developed parallel. The training results of these networks are clearly weaker than the networks destined for determining individual properties. The reason for this is probably insufficient network training. With the same number of patterns that were used in training of the single-output networks, three-output networks were trained here (the network generated times of three segments of the process), which probably impeded the development of the dependence between the input and output values. In the case of training sets (based on experimental data), it is possible to significantly improve the quality of their prediction by rounding the segments' forecast periods into full hours. However, this step has not been implemented, since in the authors' estimation this will cause a significant deterioration of the network predictions for nontraining cases. Similar results were obtained by 
Table 10 Table of nitriding segmentation prediction for selected cases of construction steels and cast irons

\begin{tabular}{|c|c|c|c|c|c|c|c|c|c|c|}
\hline & \multicolumn{5}{|c|}{ Construction steels } & \multicolumn{5}{|c|}{ Cast irons } \\
\hline & Real & ANN1 & ANN2 & ANN group & Abs. difference & Real & ANN1 & ANN2 & ANN group & Abs. difference \\
\hline \multicolumn{11}{|c|}{ First saturation segment time A1 (h) } \\
\hline 1 & 6.0 & 9.2 & 9.2 & 9.2 & 3.2 & 6.0 & 9.0 & 4.0 & 6.5 & 0.5 \\
\hline 2 & 6.0 & 6.8 & 6.2 & 6.5 & 0.5 & 6.0 & 6.0 & 6.0 & 6.0 & 0.0 \\
\hline 3 & 8.0 & 6.8 & 6.2 & 6.5 & 1.5 & 8.0 & 8.0 & 8.0 & 8.0 & 0.0 \\
\hline 4 & 4.0 & 3.7 & 2.9 & 3.3 & 0.7 & 4.0 & 4.0 & 4.0 & 4.0 & 0.0 \\
\hline 5 & 6.0 & 5.3 & 6.2 & 5.8 & 0.2 & 6.0 & 6.0 & 6.0 & 6.0 & 0.0 \\
\hline 6 & 2.0 & 5.4 & 6.2 & 5.8 & 3.8 & 12.0 & 9.0 & 12.0 & 10.5 & 1.5 \\
\hline 7 & 12.0 & 9.2 & 9.2 & 9.2 & 2.8 & 9.0 & 9.0 & 4.0 & 6.5 & 2.5 \\
\hline 8 & 9.0 & 9.2 & 9.2 & 9.2 & 0.2 & 12.0 & 9.0 & 12.0 & 10.5 & 1.5 \\
\hline 9 & 12.0 & 48.5 & 103.0 & 75.7 & 63.7 & 6.0 & 9.0 & 4.0 & 6.5 & 0.5 \\
\hline 10 & 6.0 & 9.3 & 9.2 & 9.3 & 3.3 & 6.0 & 6.0 & 4.0 & 5.0 & 1.0 \\
\hline \multicolumn{11}{|c|}{ Annealing segment time D1 (h) } \\
\hline 1 & 0.0 & 0.0 & 0.0 & 0.0 & 0.0 & 0.0 & 0.0 & 0.0 & 0.0 & 0.0 \\
\hline 2 & 2.0 & 1.7 & 1.9 & 1.8 & 0.2 & 2.0 & 2.0 & 2.0 & 2.0 & 0.0 \\
\hline 3 & 2.0 & 1.7 & 1.9 & 1.8 & 0.2 & 2.0 & 2.0 & 2.0 & 2.0 & 0.0 \\
\hline 4 & 2.0 & 2.2 & 2.5 & 2.4 & 0.4 & 2.0 & 2.0 & 2.0 & 2.0 & 0.0 \\
\hline 5 & 2.0 & 2.2 & 1.9 & 2.0 & 0.0 & 2.0 & 2.0 & 2.0 & 2.0 & 0.0 \\
\hline 6 & 2.0 & 2.2 & 1.9 & 2.0 & 0.0 & 0.0 & 0.0 & 0.0 & 0.0 & 0.0 \\
\hline 7 & 0.0 & 0.0 & 0.0 & 0.0 & 0.0 & 0.0 & 0.0 & 0.0 & 0.0 & 0.0 \\
\hline 8 & 0.0 & 0.0 & 0.0 & 0.0 & 0.0 & 0.0 & 0.0 & 0.0 & 0.0 & 0.0 \\
\hline 9 & 0.0 & -10.2 & -22.6 & -16.4 & 16.4 & 0.0 & 0.0 & 0.0 & 0.0 & 0.0 \\
\hline 10 & 0.0 & 0.0 & 0.0 & 0.0 & 0.0 & 2.0 & 2.0 & 2.0 & 2.0 & 0.0 \\
\hline \multicolumn{11}{|c|}{ Second saturation segment time A2 (h) } \\
\hline 1 & 0.0 & -0.1 & -0.1 & -0.1 & 0.1 & 0.0 & 0.0 & 0.0 & 0.0 & 0.0 \\
\hline 2 & 0.0 & 0.0 & 0.5 & 0.3 & 0.3 & 0.0 & 0.0 & 0.0 & 0.0 & 0.0 \\
\hline 3 & 0.0 & 0.1 & 0.5 & 0.3 & 0.3 & 0.0 & 0.0 & 0.0 & 0.0 & 0.0 \\
\hline 4 & 4.0 & 3.7 & 3.3 & 3.5 & 0.5 & 4.0 & 4.0 & 4.0 & 4.0 & 0.0 \\
\hline 5 & 0.0 & 0.9 & 0.5 & 0.7 & 0.7 & 0.0 & 0.0 & 0.0 & 0.0 & 0.0 \\
\hline 6 & 2.0 & 0.9 & 0.5 & 0.7 & 1.3 & 0.0 & 0.0 & 0.0 & 0.0 & 0.0 \\
\hline 7 & 0.0 & -0.2 & -0.1 & -0.1 & 0.1 & 0.0 & 0.0 & 0.0 & 0.0 & 0.0 \\
\hline 8 & 0.0 & -0.2 & -0.1 & -0.1 & 0.1 & 0.0 & 0.0 & 0.0 & 0.0 & 0.0 \\
\hline 9 & 0.0 & -23.7 & -52.5 & -38.1 & 38.1 & 0.0 & 0.0 & 0.0 & 0.0 & 0.0 \\
\hline 10 & 0.0 & -0.1 & -0.1 & -0.1 & 0.1 & 0.0 & 0.0 & 0.0 & 0.0 & 0.0 \\
\hline
\end{tabular}

Afzaal [64] who investigated the relationship between hardness and thickness of the nitrided layer and process parameters for gas nitriding. He suggests that the results of reverse modeling have high percentage error because the data points used for training are not unique.

In the literature, no reports were found on modeling of nitriding under reduced pressure. Genel [37] used a backpropagation (BP) algorithm to train a multilayer feed-forward, a neural network for modeling of complex linear and nonlinear relationships between ion nitrided case depth with chromium content as well as process time. Since the nature of the ion nitriding process is different from nitriding under reduced pressure, a qualitative comparison of both models is difficult. Zhecheva et al. [38] confirmed that ANN models can be created and used to correlate between processing parameters of nitriding and hardness of titanium alloys as well as it can also be used to optimize the processing parameters and alloy composition in order to achieve desired properties for various applications, but their experiments are based on gas nitriding what makes comparison impossible.

Guo et al. [65] used a BP algorithm to training model to modeling the correlation between processing parameters and properties of maraging steels. He reports a general observation that the training time increases dramatically when the number of outputs increases. This is convergent with observations taken during the creation of the above models. 
Therefore, setting up a series of ANN models where each model deals with only one output value significantly simplifies and speeds up the training of the ANN model.

\section{Conclusion}

The neural network model and its training procedures based on data mining in the application to the monitoring and control of low-pressure nitriding process for creation of lowfrictional coatings on gray irons and steels used for the piston rings manufacturing were studied. On the basis of the real low-pressure nitriding processes of structural, tool and cast steels, a training base was built, and a model of the nitriding process under reduced pressure was created. The properties of nitrided layers after nitriding processes were analyzed: surface hardness, diffusion layer thickness as well as $\gamma^{\prime}$ phase thickness depending on the material and chemical composition and parameters of the process: temperature and process segmentation. The hypothesis was confirmed that it is possible to construct an industrial application of low-pressure nitriding based on artificial neural networks, and in particular to investigate the suitability of specific neural network architectures: multilayer perceptron networks (MLP) and radial baseline (RBF) based networks for multiphase diffusion kinetics in low-pressure nitriding. In addition, it has been shown that constructing networks that determine single end properties of a material (constructing specialized networks) gives more accurate forecasting results than the use of general networks that simultaneously predict several material features. Additionally, it has been demonstrated that the perceptrons with nonlinear sigmoidal activation functions (MLP) map better the mathematical relationships of kinetic multiphase diffusion than radial neurons with Gaussian activation functions (RBF).

Acknowledgements The work has been done under Measure 1.2Sectoral Research \& Development programs of Program Operacyjny Inteligentny Rozwój 2014-2020 (Smart Growth Operational Program 2014-2020) co-funded by European Regional Development Fund. The project: "Gradient low-friction coats produced by means of a hybrid FineLPN process, nanostructured with $\mathrm{MoS}_{2}$ and rGO particles for use in aircraft sealing." Contract Number: POIR.01.02.00-000011/15 (NIWAG).

\section{Compliance with ethical standards}

Conflict of interest The authors declare that they have no conflict of interest.

Open Access This article is distributed under the terms of the Creative Commons Attribution 4.0 International License (http://creativecommons. org/licenses/by/4.0/), which permits unrestricted use, distribution, and reproduction in any medium, provided you give appropriate credit to the original author(s) and the source, provide a link to the Creative Commons license, and indicate if changes were made.

\section{References}

1. Mang A, Bobzin K, Bartels T (2010) Industrial tribology: tribosystems, friction, wear and surface engineering. Wiley-VCH Verlag GmbH \& Co., Weinheim

2. Williams $\mathbf{J}$ (ed) (2005) Boundary lubrication and friction. In: Engineering tribology. Cambridge University Press, Cambridge, pp 348-380

3. Neville A, Morina T, Haque M (2007) Compatibility between tribological surfaces and lubricant additives-how friction and wear reduction can be controlled by surface/lubes synergies. Tribol Int 40:1680-1695

4. Ostapski W (2011) Analysis of thermo-mechanical response in an aircraft piston engine by analytical, FEM, and test-stand investigations. J Therm Stress 34:285-312

5. Sherrington I, Smith EH (1985) Experimental methods for measuring the oil-film thickness between the piston-rings and cylinder-wall of internal combustion engines. Tribol Int 18:315-320

6. Kamal M, Ali A, Xianjun $\mathrm{H}$ et al (2016) Improving the tribological characteristics of piston ring assembly in automotive engines using $\mathrm{Al}_{2} \mathrm{O}_{3}$ and $\mathrm{TiO}_{2}$ nanomaterials as nano-lubricant additives. Tribol Int 103:540-554

7. Yamagata $H$ (2005) The science and technology of materials in automotive engines. Woodhead Publishing Limited, Cambridge

8. Zabala B, Igartua A, Fernández X et al (2017) Friction and wear of a piston ring/cylinder liner at the top dead centre: experimental study and modeling. Tribol Int 106:23-33

9. Lin J, Wei R, Bitsis DC (2016) Development and evaluation of low friction TiSiCN nanocomposite coatings for piston ring applications. Surf Coat Technol 298:121-130

10. Friedrich C, Berg G, Broszeit E et al (1997) PVD CrxN coatings for tribological application on piston rings. Surf Coat Technol 97:661-668

11. Dahm KL, Dearnley PA (2002) Novel plasma-based coatings for piston rings. Tribol Ser 40:243-246

12. Babu MV, Kumar RK, Prabhakar O, Shankar NG (1996) Simultaneous optimization of flame spraying process parameters for high quality molybdenum coatings using Taguchi methods. Surf Coat Technol 79:276-288

13. Arps JH, Page RA, Dearnaley G (1996) Reduction of wear in critical engine components using ion-beam-assisted deposition and ion implantation. Surf Coat Technol 84:579-583

14. Bindumadhavan PN, Makesh S, Gowrishnkar N et al (2000) Aluminizing and subsequent nitriding of plain carbon low alloy steels for piston ring applications. Surf Coat Technol 127:251-258

15. Holmberg K, Matthews A (1994) Coatings tribology. In: Dowson D (ed) Tribology series. Elsevier, Amsterdam

16. Pinedo CE (2003) The use of selective plasma nitriding on piston rings for performance improvement. Mater Des 24:131-135. https://doi.org/10.1016/S0261-3069(02)00121-8

17. Swift KG, Booker JD (2013) Manufacturing process selection handbook. Butterworth-Heinemann, Oxford

18. Vetter J, Barbezat G, Crummenauer J, Avissar J (2005) Surface treatment selections for automotive applications. Surf Coat Technol 200:1962-1968. https://doi.org/10.1016/j.surfcoat.2005. 08.011

19. Ferreira MG, Zheludkevich ML, Tedim J (2011) Advanced protective coatings for aeronautical application. Nanocoat Ultra Thin Films 9:235-279

20. Prado FE, Hilal M, Chocobar-Ponce S et al (2016) Chromium and the plant: a dangerous affair? In: Ahmad P (ed) Plant metal interaction. Elsevier, Amsterdam, pp 149-177

21. Oze C, Bird DK, Fendorf S (2007) Genesis of hexavalent chromium from natural sources in soil and groundwater. Proc Natl 
Acad Sci 104:6544-6549. https://doi.org/10.1073/pnas. 0701085104

22. Ali MK, Xianjun H, Mai L et al (2016) Reducing frictional power losses and improving the scuffing resistance in automotive engines using hybrid nanomaterials as nano-lubricant additives. Wear 364-365:270-281. https://doi.org/10.1016/j.wear.2016.08. 005

23. He Z, Que W (2016) Molybdenum disulfide nanomaterials: structures, properties, synthesis and recent progress on hydrogen evolution reaction. Appl Mater Today 3:23-56. https://doi.org/10. 1016/j.apmt.2016.02.001

24. Karamış MB, Yıldızlı K, Çakırer H (2004) An evaluation of surface properties and frictional forces generated from $\mathrm{Al}-\mathrm{Mo}-\mathrm{Ni}$ coating on piston ring. Appl Surf Sci 230:191-200. https://doi. org/10.1016/j.apsusc.2004.02.053

25. Gustavsson F, Jacobson S, Cavaleiro A, Polcar T (2013) Frictional behavior of self-adaptive nanostructural Mo-Se-C coatings in different sliding conditions. Wear 303:286-296. https://doi. org/10.1016/j.wear.2013.03.032

26. Jordan D (2009) Vacuum gas nitriding furnace produces precision nitrided parts. Heat Treat Prog 9:45-48

27. Gawroński Z, Sawicki J (2006) Technological surface layer selection for small module pitches of gear wheels working under cyclic contact loads. Mater Sci Forum 513:69-74. https://doi.org/ 10.4028/www.scientific.net/MSF.513.69

28. Kula P, Wolowiec E, Pietrasik R et al (2013) Non-steady state approach to the vacuum nitriding for tools. Vacuum 88:1-7. https://doi.org/10.1016/j.vacuum.2012.08.001

29. Kosikowski M, Suszyński Z, Olik R et al (2009) The application of artificial neural networks and evolutionary algorithm for the designing of gas nitriding process. Intell Inf Eng Syst 13:33-39

30. Ratajski J, Olik R, Suszko T et al (2010) Design, control and in situ visualization of gas nitriding processes. Sensors 10:218-240. https://doi.org/10.3390/s100100218

31. Sawicki J, Górecki M, Kaczmarek $Ł$ et al (2013) Increasing the durability of pressure dies by modern surface treatment methods. Chiang Mai J Sci 40:886-897

32. Bhadeshia HKDH (2009) Neural networks and information in materials science. Stat Anal Data Min 1:296-305. https://doi.org/ 10.1002/sam.10018

33. Bhadeshia HKDH, Dimitriu RC, Forsik S et al (2009) Performance of neural networks in materials science. Mater Sci Technol 25:504-510. https://doi.org/10.1179/174328408X311053

34. Genel K, Ozbek I, Kurt A, Bindal C (2002) Boriding response of AISI W1 steel and use of artificial neural network for prediction of borided layer properties. Surf Coat Technol 160:38-43

35. Song RG, Zhang QZ (2001) Heat treatment technique optimization for 7175 aluminium alloy by an artificial network and a genetic algorithm. J Mater Process Technol 117:84-88

36. Xu L, Xing J, Wei S et al (2007) Optimization of heat treatment technique of high-vanadium high-speed steel based on backpropagation neural networks. Mater Des 28:1425-1432. https:// doi.org/10.1016/j.matdes.2006.03.022

37. Genel K (2003) Use of artificial neural network for prediction of ion nitrided case depth in Fe-Cr alloys. Mater Des 24:203-207. https://doi.org/10.1016/S0261-3069(03)00002-5

38. Zhecheva A, Malinov S, Sha W (2005) Simulation of microhardness profiles of titanium alloys after surface nitriding using artificial neural network. Surf Coat Technol 200:2332-2342. https://doi.org/10.1016/j.surfcoat.2004.10.018

39. Lipiński D, Ratajski J (2007) Modeling of microhardness profile in nitriding processes using artificial neural network. Lect Notes Artif Intell 4682:245-252

40. Oltean S-E (2015) Modeling the workpiece heating on a plasma nitriding equipment using neural networks. Procedia Technol 19:562-568. https://doi.org/10.1016/j.protcy.2015.02.080
41. Yetim AF, Codur MY, Yazici M (2015) Using of artificial neural network for the prediction of tribological properties of plasma nitrided 316L stainless steel. Mater Lett 158:170-173. https://doi. org/10.1016/j.matlet.2015.06.015

42. Zinchenko VM, Georgievskaya BV, Olovyanishnikov VA, Kuznetsov VV (1984) New methods of gas carburization and nitriding. Met Sci Heat Treat 26:775-780

43. Jordan D, Antes H, Osterman V, Jones T (2008) Vacuum nitriding of 4140 steel. Heat Treat Prog 3-4:33-38

44. Filetin T, Zmak I, Novak D (2005) Determining nitriding parameters with neural networks. J ASTM Int 2:133-143

45. Khalaj G (2013) Artificial neural network to predict the effects of coating parameters on layer thickness of chromium carbonitride coating on pre-nitrided steels. Neural Comput Appl 23:779-786. https://doi.org/10.1007/s00521-012-0994-2

46. Gianola D, Okut H, Weigel KA, Rosa GJ (2011) Predicting complex quantitative traits with bayesian neural networks: a case study with Jersey cows and wheat. BMC Genet 12:87. https://doi. org/10.1186/1471-2156-12-87

47. Okut H, Wu X-L, Rosa GJ et al (2013) Predicting expected progeny difference for marbling score in Angus cattle using artificial neural networks and Bayesian regression models. Genet Sel Evol GSE 45:34. https://doi.org/10.1186/1297-9686-45-34

48. Hornik K, Stinchcombe M, White H (1989) Multi-layer feed forward networks are universal approximations. Neural Netw 2:359-366

49. Wang S, Hsu T (1998) Perceptron-perceptron net. Pattern Recognit Lett 19:559-568

50. Rumelhart D, Hinton G, Wiliams R (1986) Learning internal representations by error propagation. MIT Press, Cambridge

51. Cybenko G (1988) Continuous valued neural networks with two hidden layers are sufficient. Tufts University, Medford

52. Rosenblatt F (1958) The perceptron: a probabilistic model for information storage and organization in the brain. Psychol Rev 65:386-408

53. Minsky M, Papert S (1988) Perceptrons an introduction to computational geometry. MIT Press, Cambridge

54. Feng J, Tirozzi B (1999) Learning in a higher-order simple perceptron. Mat Comput Model 30:217-223

55. Rosenblatt F (1962) Principles of neurodynamics. Spartan Books, New York

56. Moody J, Darken C (1989) Fast learning in networks of locallytuned processing units. Neural Comput 1:281-294

57. Lehtokangas M, Saarinen J (1998) Centroid based multilayer perceptrons networks. Neural Process Lett 7:101-106

58. Rumelhart D, McClelland J (1986) Parallel distributed processing. MIT Press, Cambridge

59. Haykin S (1994) Neural networks: a comprehensive foundation. Prentice Hall, New York

60. Fausett L (1994) Fundamentals of neural networks. Prentice Hall, New York

61. Patterson D (1996) Artificial neural networks. Prentice Hall, Singapore

62. Software Dell (2014) Statistica. TIBCO Software Inc., Palo Alto

63. Aitkin M, Foxall R (2003) Statistical modelling of artificial neural networks using the multi-layer perceptron. Stat Comput 13:227-239

64. Afzaal U (2006) Modeling of gas nitriding using artificial neural networks. MSc thesis, McMaster University

65. Guo Z, Sha W (2004) Modelling the correlation between processing parameters and properties of maraging steels using artificial neural network. Comput Mater Sci 29:12-28

Publisher's Note Springer Nature remains neutral with regard to jurisdictional claims in published maps and institutional affiliations. 